\title{
An Analysis of Song Xiaozong's Response to the "Resurgence of the Road" in the Period of Social Transformation
}

\author{
Kaiyue Bian \\ PLA University of Science and Technology College of Science, Nanjing 21000, China \\ 248653308@qq.ocm
}

Keywords: Song Xiaozong, Resurgence of the Road, Social transformation period, Effect.

\begin{abstract}
Song Xiaozong was the emperor of the Southern Song Dynasty. In the face of the grim situation of internal and external tragedy, he took a series of vigorous measures to make snap reform, social politics, economy and military have been considerable development, and created the history of the Southern Song Dynasty of the heyday of the situation, known as the "Xiaoyuan You", "Yuanyou" for the Northern Song Dynasty Zhezong's reign, it was the most powerful era of the Northern Song Dynasty, Song Xiaozong also known as "Resurgence of the king", but at the same time should also see that Xiaozong's ruling performance is limited, and that the situation of the weak and poor people in the Song Dynasty is not fundamentally changed, this is both the Southern Song Dynasty society itself with the existence of all kinds of ills, but also with the Song Xiaozong personal ability and rule of governance.
\end{abstract}

\section{Introduction}

In the history of the Southern Song Dynasty, Song Xiaozong Zhao Shen is a relatively active as an emperor, known as "the first emperor to the South stand". As a micro-imperial clan disciples, Song Taizu Zhao Kuangyin seven of the grandson, Zhao Shen was selected by Song Gaozong, unexpectedly became the heir to the throne, following the throne, Xiaozong aspiring to restoring the Central Plains, resurgence countries, showing a vigorous and aggressive atmosphere that is distinct from the content to exercise sovereignty over a part of the country and do not seek long-term interests, only figure immediate survival with Gaozong. In its reign, the domestic order is stable, political clear, economic development, cultural prosperity, which created the history of the Southern Song Dynasty heyday, known as "the rule of dry governance".

\section{The basic content of Song Xiaozong's "Resurgence of the Road"}

Shaoxing thirty-two years (1162) in June, Song Xiaozong ascended the throne at the beginning, on the line up and sleeves ready to do a big, his ambitious, determined to recover the Central Plains, the use of the main battle representative Zhang Jun's proposal, then launched in winter once to recover the lost land for the purpose of the Northern Expedition. However, due to the gap between national strength and strength, Song in the mark from the "overnight collapse", the defeat so that Song Xiaozong soberly aware of the Southern Song soldiers weak, hardship, lack of financial status quo. Therefore, he rationally transferred the strategy of governing the country from "foreign against the enemy" to "domestic governance", focusing on the internal political, economic, military and other aspects of the Southern Song Dynasty to rectify and reform.

2.1 Politically, while trying to rectify the long-standing and increasingly serious drawbacks in order to achieve the revitalization of the national character as soon as possible

Gaozong left the mess, so that took the monarchical filial piety face a severe test, since the ambition of the filial piety, to exclude all kinds of resistance to the corruption of the political reform, to stabilize the people to revitalize the national potential. Ascended the throne soon, he announced to the minister, "I have no harm to the world, today's harm, care about because of customs, if the system changes, cheers in this" [1]. Made it clear that the reform of the past few decades, the real implementation of the long-term resurgence countries. 


\subsubsection{Revitalize the government, the power of the true remonstrance of the wind}

In order to revitalize the affairs of state, first from the reign of emperor Xiaozong to correct various unjust case of misjudged cases. The throne for second months, he formally issued edicts vindication for Yue Fei, Issued a decree to recover him and his son Yue Yun's official, to a grand ritual re-funeral, in his hometown built "martyrs" for people to commemorate. Followed by the beginning to clean up all kinds of injustice, for those who have died, such as Li Guang, Zhao Ding, Fan Chong and others, are to restore their reputation, favor their children and grandchildren; for those who are still alive, such as Xin times, Hu Quan And so on, mostly re-use. Filial piety this move won the hearts of the people from top to bottom lifted.

In order to change the period of Gaozong, due to the authority of the righteousness, the exclusion of different, the situation of the road closed, Xiaozong also advocated direct reminder of the wind, to encourage officials to actively participate in the national revival of government affairs. He clearly declared: "I will accept the bold, accept the outspoken. Speaking count, reward is clear; do not help in reason, the crime is not accumulated." [2] In the positive encouragement of filial piety, officials or letters or playing, have bluntly admonish, smooth on politics.

\subsubsection{Elimination of redundant staff, strict selection of officials}

Since the Northern Song Dynasty, officials have been very serious phenomenon of redundancy, historical data, said, "His official I do not know their duties, often eighty-nine." [3] For this filial piety promulgated two edicts: one when in the outskirts of the worship of heaven and earth, no recommendation to the court for their children as officials; the second suspended directly to the emperor played a chapter. And then provides: all officials at all levels over 70 years of age, no special circumstances, should automatically request retirement. At the same time, he began to prepare to adjust the official system in order to fundamentally solve the problem of redundant officials. As a result of the vital interests of many officials, against the sound of the wind, filial piety to withstand the pressure, adhere to the implementation. "Those who are not qualified to be appointed people, be sure to leather to go." [4] Such as in the Department, Shangshu and assistant minister of the officials from the Northern Song Dynasty more than 90 people to streamline more than 70 people; officials of the Department of Shangshu members from Shaoxing nearly 100 people reduced to more than 40 people. But also greatly reduced the number of officials at the levels of the younger generation to get official positions.

The examination of imperial examinations, the appointment of ministers and the recommendation of the minister in service was the three main approaches for selecting officials in the song dynasty. Among them, the latter two methods there is no clear standard, no strict auditing system, resulting in a lot of official corruption to collusion. To this end, Xiaozong establish a strict system of official examination, for the official promotion, in addition to the normal promotion exam, when Jiansi and Junshou took office must carry a copy of the emperor's producer, record the merits and demerits of the work as evidence, for negligence of favoritism of the officials, regardless of the level of posts, all severely punished; for officials to be associated with the responsibility, if the move is non-human, will subject to the corresponding punishment.

\subsubsection{To break the rules, and not to stick to one pattern to employ or appoint people according to their merits}

Xiaozong pay great attention to collecting talent, promotion and appointment of new people, the first 9 times open examination, a total of 3873 people, and repeatedly stressed: for talent, it is necessary to conduct a comprehensive study, strict requirements, and not because of doing something frustrated, later do not do it again, demanding perfect, no shortcomings. "Know the ritual who do not have to know music, musicians do not have to know the punishment, if it was improper number of easy, should be long for the responsibility." [5] At the same time he broke the seniority, step by step rules, and exceptional promotion of a large number of people with real talent. Such as the leaves due to good at the chapter of literature, from the book sacrifice to the prime minister, before and after a year; Ye Heng from a small magistrate continued to rise to the phase, but also ten years. 


\subsection{Economically rectify taxes and corvee, set up a cause of benefit to the people of the country, and remove all kinds of drawbacks}

\subsubsection{Reform taxes and corvee, and strive to the people recuperate policy}

Southern Song tax names, the amount of heavy, so that people cannot maintain basic life. For the majority of the people of the poor situation, Xiaozong realized that "the people cannot be trapped." [6] He has repeatedly reminded officials at all levels to pay attention to civil suffering, remove those additional convergence to ease the burden on the people, there is no ability to pay the farmers, a large number of exempt from Zhejiang, Jiangdong, Hubei, Huai and other places rice 1.7 million stone and the money and the total money of 26 million Min; and actively improve the service system, the implementation of uniform law, to change the stealing service heavy, the ills of unfair apportionment.

\subsubsection{Reduce redundancy, vigorously promote frugality}

Since the Northern Song Dynasty, the phenomenon of overdue expenditure has been very serious, only the official salary of a, in addition to the normal wages there are brocade, salary money, official salary, give, public money, coupons and many other names, Which makes the already very tight financial more difficult, Xiaozong ascended the throne, it made it clear that "from the province, no to trouble", and decided to start from their own and the court minister. Such as the next day, filial piety announced the suspension of all into the birthday, three months later, and stops the celebration (filial day birthday) celebration, abolition of catering Department, dedicated to music and dance place and other institutions.

And cut off the action of the red echoed, filial piety and vigorously promote the thrift. He believes that "'humble and courteous people will not insult others; their frugal people will not snatch others, respectfully frugal about the body and mind, the basis of conservation of virtue". [7] Therefore, he repeatedly decreed the luxury of the wind is strictly prohibited. In May 1313, he reiterated the ban on "decorated with gold jade" of the order, requiring the dignity of the officials from the frugal, in order to set an example for people, filial piety to set an example, the implementation of frugality. At that time some people praised the filial piety "holy simple and frugal, although the ancient emperors are not also". [8]

\subsection{Military expansion of military preparedness, make the army strong and repair equipment}

A strong enemy is waiting side by side, national calamity improve the country's military power, become a matter of urgency of Xiaozong; not to brave march into the Central Plains, retaliate against the hatred, scrub shame, has been the heart of the unforgettable plan. Therefore, he vigorously promoted the positive advocates of anti-gold officials, especially in the quarry of the war made great efforts Yu Yunwen, and anti-gold representative Zhang Jun and others, relying on them to strengthen the army building, improve the quality of the army, and promote the cause of reunification carry out.

\subsubsection{Increased armaments to ensure munitions}

For a long time do not speak of armed, armaments bad, lack of equipment, Xiaozong ordered all large weapons and related equipment. Each region has a certain manufacturing indicators, and must be completed within the specified time, sent to the designated location. In order to prevent some officials perfunctory, shoddy, Xiaozong special order of the relevant departments of various types of equipment to develop a unified specification requirements, issued around the implementation of reference. Where the equipment does not meet the requirements, all returned to the re-creation, and held accountable officials of the responsibility. For the timely allocation of military supplies and supplies, but also in Jiangsu and Zhejiang, Jinghu, Huai-Guang, Fujian and other roads since the resumption of the Northern Song Dynasty since the operation of the institutions, the Huai-dong collusion Huai Xi total collusion, guards Ma Jun Division animal husbandry also Moved from Lin'an to Zhenjiang, ready to send troops, the cavalry can go directly to the river fighting.

\subsubsection{Unattended selection of generals}

Expand the quota of the military examination system, improve the status and treatment of the military, on the military machine experienced and peerless feat scholar, directly assigned to the position of senior officers, the level of the general are assigned to the garrison as a machine "Counselor". At the same time, repeatedly asked the fumiomi generals are not limited to restrictions, 
recommend excellent military talent, for a large number of military talents to stand out to provide a good opportunity.

\subsubsection{Increasing the effectiveness of rectification justice volunteer}

The so-called "utility", similar to today's volunteers, because they are designed to combat war for the occupation, the fighting force is generally forced to force a number of compulsory soldiers, and the government to their treatment is also more generous, such as double payment of salaries, free from tattoos on the face and so on. In the strong implementation of Xiaozong, the total number of front-line troops, the effectiveness of the proportion of up to 30 percent or more, these effects for the excitement of the general morale, improve the combat effectiveness of the army has a great help.

The militia was a civil armed organization spontaneously organized by the people in the early years of the Northern Song Dynasty and the Southern Song Dynasty to fight against the invaders, and became an important military force for the government of the Southern Song Dynasty to resist the enemy. Xiaozong changed the case of Gaozong let the policy of self-suicide, all kinds of loyalty army to conduct a comprehensive rectification, selectively put them into the government's unified command system. For example: cut old to weak, keep strong deposit fine; give formal designation, straighten out the relationship between command; update weapons and equipment, improve the treatment of salary and so on. At the same time to re-recruit and set up a new army to enrich. After some efforts, volunteer army like the regular military appearance greatly improved, combat effectiveness is also significantly enhanced.

\section{Song Xiaozong "Resurgence of the Road" effect and reasons}

Song Xiaozong period is the Southern Song Dynasty from breaking open to recovery, from the depression to the revitalization of the times. In order to change the civilian military attache, carefree and contented wandering play, only the immediate, regardless of the future status of ease, he established the "Domestic governance, foreign against the enemy" policy, the reform, rectification and rectification of the political, economic and military systems in the Southern Song Dynasty, to the ups and downs of the Southern Song dynasty brought a vigorous vitality. Of course, any historical figures of the activities will be affected by the internal and external factors, Song Xiaozong determined to make progress, great care, but failed to complete the resumption of lost land, which both external and internal reasons, both objective external environment influence, but also with the Song Xiaozong own ability to have a great relationship.

\subsection{Internal reasons: strong traditions follow the forces and conservative consciousness squeeze the space of social and political reform}

The Southern Song Dynasty is a direct continuation of the regime of the Northern Song Dynasty. It inherited the basic national policy of the system of the Northern Song Dynasty, and inherited the ills of the accumulation of the Northern Song Dynasty regime. The Northern Song Dynasty since the first founder of a dynasty set on the "pay attention to civilian officials and military officials in contempt" of the basic national policy. Since then, the soldier is no longer a glorious thing, the pre-Qin bloody and Han and Tang's glory is gone. There are also many problems in the system of the Northern Song Dynasty. For example, in order to reduce the power of the monarchical power, the Song Dynasty put the right in the administrative, military and financial affairs, and went to the governorate, the Privy Council and the three divisions respectively. Three of their own political, there has been the emptiness of the treasury, the Privy Council does not know is still recruiting, the people have long been poor, the Ministry of Finance is still in the case of extortion. In order to remove the ills, you need to carry out the necessary innovation, however, "today's disaster, people know Cai Jing, Wang Fu of the crime, and do not know the world chaos because Wang Anshi." [9] Southern Song Dynasty founding father Song Gaozong this sentence, but the reasons for the demise of the Northern Song Dynasty attributed to Wang Anshi and its reform movement. From then on to deny the future may be any innovation activities, even Song Xiaozong, who is superior to the emperors of all countries, it can only repair the shortcomings of the patch, and cannot be large-scale changes and innovation, which in a way affected the revitalization of national strength. 


\subsection{External reasons: a "little Yao and Shun," said Jin Shizong, Dading of the occasion of the political clear and from top to bottom unity, and did not take the gap between the Xiaozong}

Zhenglong six years (1161), Jin Hailing Emperor Wan Yanliang regardless of "Shaoxing peace negotiations" to the power of the country launched a large-scale war on the Southern Song Dynasty, an attempt to kill Song, at this time the Hailing Emperor led the army to walk between JAC, The Jin Dynasty imperial clan, Dongjing stay Wan Yanyong ascended the throne in Liaoyang, change reign title Dading, is Jin Shizong. Jin Shizong ascended the throne, based on a clear understanding of the situation inside and outside the situation, Due to the situation and make painstakingly managed to properly handle the "persuasion before the fumiomi generals surrender, establish the authority", "the suppression of the uprising stabilizing the domestic political situation", "restoration and peaceful relations between the Southern Song" and other major issues. "Longxing peace negotiations", the Jin Dynasty and the Southern Song Dynasty have entered the important historical period, Jin Shizong on the one hand with the "peace negotiations" in the provisions of the Jin Dynasty superior position to suppress the Southern Song Dynasty, on the other hand, Foreign affairs, he also in the same way to deal with the relationship between Gaoli and the Xixia, Jin Shizong period of the northern political situation and national relations and peaceful development. The peaceful environment brought by the good neighborly policy provides favorable conditions for Jin Shizong's attempt to seek good fortification. He is appointing virtuous talented people, pay attention to the historical policy, the slaves free, reducing tax, pay attention to education. "Jinsi-Shizong JiSan" praised: " At that time, the ministers loyal to their duties, the upper and lower levels live in harmony, every family is full of food and clothing, rich in life, in charge of the criminal law department of one year may be convicted of seventeen people, there may be twenty people, known as little Yao and Shun ". Jin Shizong 30 years of operation, so that the Jin Dynasty toward a comprehensive prosperity. Therefore, although Xiaozong period known as the "the rule of dry governance", is the best period of the Southern Song Dynasty. But Song Jin both political, economic and military aspects of strength compared to the Song in general did not have overwhelming advantage, and Song Jin between the "peace negotiations" and Jin Shizong's peace policy does make Song Xiaocong difficult to open the war, The only time with the Sichuan Yifu Yu Yunwen planning things to join forces to join forces in Henan action, but also because of Yu Yunwen's death and let the matter.

\subsection{Personal reasons: Song Xiaozong only recovery of the blog, the lack of restoration of rivers and mountains of the male figure in general, especially people who know people}

Yuan Ren Liu Yiqing in contrast to Gaozong, Xiaozong before and after the two dynasties, once said: "Gaozong dynasty, there is the restoration of the minister, no recovery of the king; Xiaozong dynasty, there is the recovery of the king, no recovery of the minister. So the war was less defeated, the whole court argued right and wrong, wronged request and words but cannot be, Xiaozong ambitious pity! [10] For Xiaozong, historians a lot of complacency, more will be attributed to the failure of the cadres of the cadres and ministers of the security of the insult. The author did not agree with this, Song Xiaozong did not complete its restoration of the vision, in addition to objective reasons at home and abroad, its ability to govern, especially the ability to use only to be questionable.

Song Xiaozong often discusses with the minister how to cultivate and use talent and other issues, and the views are quite brilliant. Such as "to have the talent of a gentleman, to have the talent of a villain. A little man has talent, but a tiger has wings. The desire of the Lord is to distinguish the evil from the positive". [11] However, from the actual situation, filial piety verbally talked and said, but in practice is the election is not allowed, Renren soon, suspicion. For example, Chunxi years right phase balance, in the hearts of Song Xiaozong, Ye Heng " In order to be able to adopt, are rich and powerful people of the strategy; if the pre-emptive, the first high-ranking position and happy to enjoy the rich and glorious, encountered difficulties only to be able to take advantage of the people, Know his importance". [12] In fact Ye Heng is a mediocre generation, no office after any achievements. Visible, Xiaozong election is not allowed. Xin Qiji serving the army, the 23-year-old in the gold medal in the capture of the rebellion Zhang Guo'an, serving the local, the performance is very good, for this generosity, that is, smart and brave big talent, Xiaozong has not been reused, showing that he lacks knowledge. Another example is the appointment of people soon, which in the choice and appointment 
of the Minister of the performance of the most obvious, the appointment of mercy depends on the rise and fall of government affairs, but Xiaozong often rush to act, suddenly changed life, as well as months more than a few days For the ruling. Reign of 27 years, a total of 15 people involved in the record, the Senate political 34 people, many of whom served only a few months only. Xiaozong appeared in person, not the candidate selection and appointment of people soon, but he wants to avoid a repeat of the past, to prevent some people too much power, out of control, eventually because he identified only with only limited capacity. This appears Xiaozong is no right to appear, but it makes it possible for those who cannot fully display the ability, mediocre but can be safe by Paul. The so-called people do their best, only make the best use, and can only be a fantasy.

Ou Yangxiu in the "New Five Dynasties History" said: "Alas! Make wares, no good material has a good craftsman; the people who run the country, without a good servant has a good monarch. Is probably the material to wait for good carpenter and a servant to wait for the emperor to enable. [13] History of mediocrity of the king, there may be outstanding ministers around, such as Tang Dezong of Li Mi, Ma Sui; Song Gaozong of Yue Fei, Han Shizhong; Ming Xizong of Yuan Chonghuan, Xiong Tingbi. Wise group of the main men must have hero, such as the Martial Emperor of Wei Qing, Huo Qubing; Emperor Guangwu of Han of Yuntai twenty-eight officers and men; Tang Taizong Ling Yange twenty-four hero. There are wise monarchs, but not to courtiers brave soldiers, since ancient times have not. Because, "side to class together, things to group points, with the Ming meet, when you face the same thing or phenomenon, you can see each other's behavior or coping with each other, those who promote the same ethical or principled approach, while living in different places, are able to respond to each other and understand each other and understand each other, only talented people can identify talented people, only smart people can identify smart people". [14] A wise and powerful monarch will have the ability to discover and reuse genius. Song Xiaozong in power of 54 million people, was not worthy of the resumption of the task of excellence is impossible, can only say that Song Xiaozong did not know the excellence, cannot fully use good talent.

\section{Summary}

In summary, Xiaozong ascended the throne later, In the face of Shaoxing since the immediate state of the country, the situation is not stable, remedy defects and rectify errors, revitalize the court of the discipline, development of the economy, make the army strong and repair equipment, the political and economic system of the Southern Song Dynasty reform and rectification, Membership to be self-government, to the twilight of the Southern Song dynasty brought a vigorous vitality. Such as the rectification of the road to choose the right, so that the Southern Song Dynasty and the decadent political wind lifted; such as rectification and taxation to help build water conservancy, so that the account increased financial improvement, "Xiao Yuan You" said; such as recruiting will be painstakingly operating late the main military force of Mongolia. Therefore, on the whole, Xiaozong rule is positive, is the most important emperor of the Southern Song Dynasty, is the history of the famous "Resurgence of the king", but also should see that Xiaozong during the reign of its performance is limited, mixed with a universal Unified Kyushu ambition burst, although this has a lot of objective factors, but more with the Song Xiaozong their ability to govern in particular, people know the ability and rule of the improperly inseparable.

\section{References}

[1] "Song Zhai Fu compiled the annual record" Volume 17 "filial piety Shaoxing thirty-two years in October has been".

[2] Bi Yuan. "Continued governance rule" Volume 137 "Shaoxing thirty-two years in June Jia Shen."

[3] "Song" volume 161 "official Zhiyi".

[4] Bi Yuan. "Continued management of governance" volume 145" Chunxi three years in December."

[5] "Emperor Song ZTE two holy government" Volume 46 "filial piety emperor six". 
[6] Bi Yuan. "Continued governance rule" Volume 26 "Chunxi four years in March".

[7] Bi Yuan. "Continued governance rule" Volume 148 "Chunxi eight years of the first month of Hai Hai."

[8] Ye Shaoweng. "Four heard of the record" B set "filial piety called Zhou Yi Gong."

[9] Li Xin Chuan. "Jian Yan since the Department of the year to record" Volume 87" Shaoxing five years in March Gengzi article".

[10] (Yuan) Liu Yiqing. Qiantang Memorial [M], Shanghai: Shanghai Ancient Books Publishing House, October 1985.

[11] "Emperor Song of the two dynasties of the Holy Communion" Volume 46.

[12] Xu Ziming. "Song Zhai Fu compiled annual record", volume 18, Beijing: Zhonghua Bookstore school-based, 1986.

[13] Ouyang Xiu. "New Five Dynasties History" Volume 31, Beijing: Zhonghua Book Company, 1974.

[14] "Qian Fu Lun" Volume 2, photocopied Wen Yuan Ge four treasures of the book. 